\title{
MAX-DOAS detection of glyoxal during ICARTT 2004
}

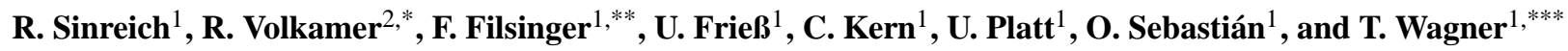 \\ ${ }^{1}$ Institut für Umweltphysik, Universität Heidelberg, Heidelberg, Germany \\ ${ }^{2}$ Massachusetts Institute of Technology, Cambridge, MA, USA \\ * now at: University of California, San Diego, La Jolla, CA, USA \\ ** now at: Fritz-Haber-Institut der Max-Planck-Gesellschaft, Berlin, Germany \\ **** now at: Max-Planck Institute for Chemistry, Mainz, Germany
}

Received: 22 August 2006 - Published in Atmos. Chem. Phys. Discuss.: 26 September 2006

Revised: 25 January 2007 - Accepted: 16 February 2007 - Published: 22 February 2007

\begin{abstract}
The direct detection of glyoxal (CHOCHO), the smallest $\alpha$-dicarbonyl, in the open atmosphere by active differential optical absorption spectroscopy (DOAS) has recently been demonstrated (Volkamer et al., 2005a) and triggered the very recent successful detection of $\mathrm{CHOCHO}$ from space (Kurosu et al., 2005; Wittrock et al., 2006; Beirle et al., 2006). Here we report the first comprehensive analysis of CHOCHO by passive multi axis differential optical absorption spectroscopy (MAX-DOAS). $\mathrm{CHOCHO}$ and $\mathrm{NO}_{2}$ slant column measurements were conducted at the Massachusetts Institute of Technology (MIT), Cambridge, USA, and on board the research vessel Ron Brown in the Gulf of Maine as part of the International Consortium for Atmospheric Research on Transport and Transformation (ICARTT) 2004 campaign. For a day with nearly clear sky conditions, radiative transfer modeling was employed to derive diurnal CHO$\mathrm{CHO}$ mixing ratios in the planetary boundary layer (PBL) for both sites. CHOCHO mixing ratios at MIT varied from 40 to $140 \mathrm{ppt}$, with peak values observed around noon. Mixing ratios over the Gulf of Maine were found to be up to 2.5 times larger than at MIT. The CHOCHO-to- $\mathrm{NO}_{2}$ ratio at MIT was $<0.03$, and enhancements of this ratio by up to two orders of magnitude were found over the Gulf of Maine. This paper focuses on the methodological aspects involved with MAXDOAS measurements of CHOCHO.
\end{abstract}

\section{Introduction}

Glyoxal (CHOCHO) is the smallest $\alpha$-dicarbonyl and is an oxidation product of numerous volatile organic compounds (VOCs) (Calvert et al., 2000; Volkamer et al., 2001; Calvert et al., 2002). Direct and time resolved CHOCHO measurements provide a useful novel indicator to constrain VOC ox-

Correspondence to: R. Sinreich

(roman.sinreich@iup.uni-heidelberg.de) idation processes (Volkamer et al., 2005a), and enable many useful applications, such as an improved source apportionment of formaldehyde (HCHO) in urban air (García et al., 2005). The atmospheric residence time of CHOCHO is limited by rapid photolysis and reaction with $\mathrm{OH}$ radicals, and is about $1.3 \mathrm{~h}$ for overhead sun conditions (Volkamer et al., 2005a). An increasing body of evidence recently suggests that volatile $\mathrm{CHOCHO}$ possibly contributes to secondary organic aerosol (SOA) formation (Liggio et al., 2005; Kroll et al., 2005; Volkamer et al., 2006). However, the atmospheric relevance of $\mathrm{CHOCHO}$ uptake on aerosols is presently not clear.

The strongest absorption bands of $\mathrm{CHOCHO}$ are located in the blue wavelength range between 420 and $460 \mathrm{~nm}$ (Volkamer et al., 2005b). These bands have recently been used to measure $\mathrm{CHOCHO}$ for the first time directly in the open atmosphere, as part of the Mexico City Metropolitan Area (MCMA) 2003 campaign, using an active differential optical absorption spectroscopy (DOAS) device (employing a Xearc light source). It has further been suggested that the detection of CHOCHO by passive DOAS, i.e. using scattered sunlight as a light source, should be feasible from groundor space-borne platforms (Volkamer et al., 2005a). Most recently measurements of $\mathrm{CHOCHO}$ from space have been accomplished by three research teams using two satellite platforms (i.e. the Ozone Monitoring Instrument (OMI) and the Scanning Imaging Absorption Spectrometer for Atmospheric Chartography (SCIAMACHY)) (Kurosu et al., 2005; Wittrock et al., 2006; Beirle et al., 2006). In this study we present the first comprehensive analysis of $\mathrm{CHOCHO}$ using passive ground-based DOAS instrumentation based on initial studies by Sinreich et al. (2004). CHOCHO observations from ground-based instruments have also been reported by Wittrock et al. (2006).

DOAS is a well established technique for the detection of trace gases in the atmosphere (Platt, 1994). The position and optical density of narrow band absorption features

Published by Copernicus GmbH on behalf of the European Geosciences Union. 

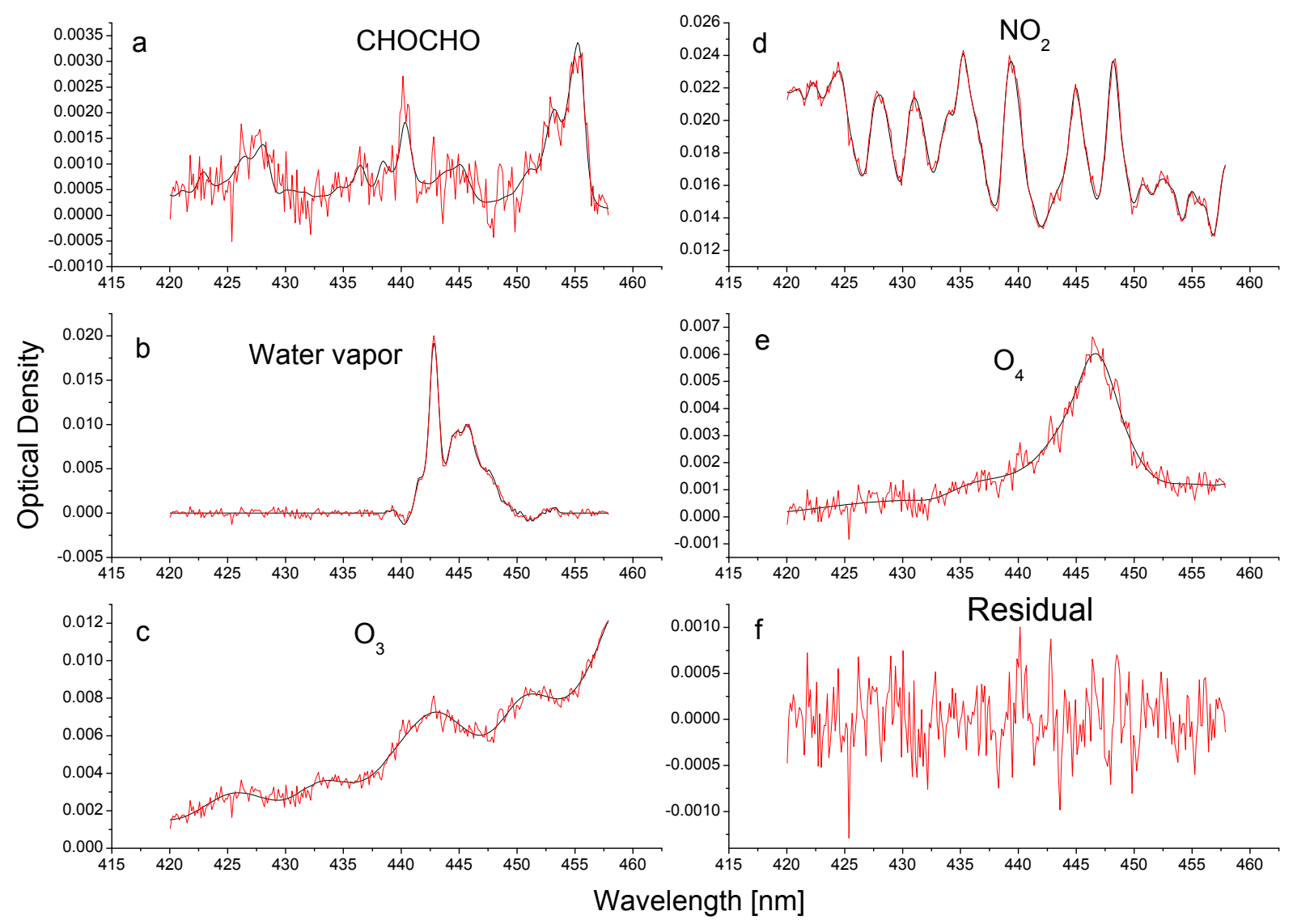

Fig. 1. CHOCHO example retrieval of a spectrum taken on 10 July 2004, 5:15PM at a $3^{\circ}$ elevation angle. The optical densities of the scaled cross-sections (black) and the sum of the scaled cross-sections and the residual (red) as a function of wavelength are plotted, (a) for CHOCHO, (b) for water vapor, (c) for $\mathrm{O}_{3}$, (d) for $\mathrm{NO}_{2}$ and (e) for $\mathrm{O}_{4}$. (f) shows the residual.

$(<5 \mathrm{~nm}$ width) in the light spectra are analyzed to selectively detect and quantify trace gases by applying Lambert-Beer's law. Like most spectroscopic techniques DOAS is inherently self-calibrating as well as contact free, it identifies the particular molecules unequivocally by their characteristic absorption structure (see Fig. 1), and allows real time measurements (Platt 1999). The DOAS technique has been used in the detection of a large variety of trace gases, including $\mathrm{NO}_{2}, \mathrm{O}_{3}$, $\mathrm{SO}_{2}, \mathrm{HCHO}, \mathrm{NO}_{3}, \mathrm{BrO}, \mathrm{OClO}$ and - as discussed in this article - CHOCHO. In contrast to active DOAS instruments, where artificial light sources are employed, passive DOAS devices use natural light sources like the sun. Measurements of scattered sunlight can be performed with a relatively simple setup and very low power consumption (Solomon et al., 1987; Otten et al., 1998; Bobrowski et al., 2003; Galle et al., 2003). "Traditional" setups point only to the zenith and are mostly sensitive to trace gases located in the stratosphere. To increase the sensitivity to trace gases close to the surface, the Multi-Axis-DOAS (MAX-DOAS) technique has been developed recently. MAX-DOAS instruments observe scattered sunlight from a variety of viewing directions. In particu- lar, high sensitivity for gases close to the ground is obtained for observation directions pointing slightly above the horizon (Hönninger and Platt, 2002; Leser et al., 2003; van Roozendael et al., 2003; Wittrock et al., 2004; Hönninger et al., 2004; Wagner et al., 2004; Heckel et al., 2005; von Friedeburg et al., 2005; Frieß et al., 2006). Furthermore, some degree of vertical resolution can be obtained by measuring along different lines of sight. In particular, when assuming a well mixed trace gas layer (e.g. within the atmospheric boundary layer), its vertical extent can be determined with good accuracy (e.g. Hönninger and Platt, 2002; Wittrock et al., 2004; Sinreich et al., 2005; Heckel et al., 2005; Frieß et al., 2006) which generally is not possible with active DOAS devices.

The primary quantity of a DOAS measurement is the "slant column density" (SCD) which is the integrated concentration along the light path, or more realistically the average integrated concentration over many possible light paths. Since the DOAS analysis is applied to the ratio of the measured spectrum and a reference spectrum which also contains a certain amount of trace gas absorption, the actual quantity 
of the DOAS measurement is the "differential slant column density" (DSCD), i.e. the difference between the actual SCD and the SCD of the reference spectrum. In contrast, the "vertical column density" (VCD) is the integrated concentration over a vertical path through the atmosphere. Thus, the VCD is independent of the particular measurement geometry and the sunlight conditions. The DSCD can be converted into VCD by dividing the DSCD by the differential air mass factor (DAMF). Thus, the air mass factor (AMF) expresses the light path ratio between the slant and the vertical path through the atmosphere. Because of the complexity of radiative transfer, AMFs are usually calculated using numerical radiative transfer models (Solomon et al., 1987; Marquard et al., 2000). The calculated (differential) AMFs can be used for inverse modeling which means that the parameters of the calculations are altered until the model output matches the measured DSCDs. In this study, we derive height information from MAX-DOAS measurements on aerosol extinction as well as on mixing ratios of $\mathrm{CHOCHO}$.

Our MAX-DOAS observations were part of the International Consortium for Atmospheric Research on Transport and Transformation (ICARTT) 2004 campaign, which took place from 1 July through 15 August 2004. A network of 6 passive DOAS devices was set up in the north-eastern USA, amongst others at the Massachusetts Institute of Technology (MIT) in Cambridge. Additionally, a MAX-DOAS device was installed on the research vessel Ron Brown which cruised through the Gulf of Maine during the measurement period. These two MAX-DOAS devices were used to measure $\mathrm{NO}_{2}, \mathrm{HCHO}, \mathrm{O}_{4}$ and also $\mathrm{CHOCHO}$.

\section{Measurement sites and instruments}

The two MAX-DOAS instruments with the capability to detect $\mathrm{CHOCHO}$ (owing to the selected wavelength range of the spectrographs) were those at MIT and RV Ron Brown. The first instrument was located on one of the buildings (Building 54, the so-called Green Building) of the MIT in Cambridge at $42.36^{\circ}$ northern latitude and $71.09^{\circ}$ westerly longitude; the instrument was pointing to the north. The second instrument was installed on the research vessel Ron Brown during its cruise in the Gulf of Maine, looking starboard. In this case, the observation azimuth varied depending on the course of the vessel.

At MIT a "Mini-MAX-DOAS" device was operated. It contained a miniature crossed Czerny-Turner spectrometer/detector unit "USB2000" from Ocean Optics Inc. with a resolution of $0.7 \mathrm{~nm}$ full width at half maximum (FWHM), projecting the spectral range from about 330 to $462 \mathrm{~nm}$ onto a one-dimensional CCD-detector with 2048 pixels. The spectrometer/detector unit was cooled to a stable temperature of $+15^{\circ} \mathrm{C}$ which minimized changes in optical properties of the spectrometer while reducing detector dark current. The scattered sunlight was collected and focused by a quartz lens and was lead into the spectrograph/detector unit by a quartz fibre bundle. To avoid condensation of water vapour, the instrument was sealed and a drying agent was included. An attached stepper motor enabled the adjustment of the viewing direction to a desired elevation angle ("elevation" is defined as the angle between the horizon and the pointing direction of the telescope). All functions were controlled by PC via USB connection.

The MAX-DOAS instrument installed on the RV Ron Brown had a separate telescope unit which collected scattered sunlight from different elevation angles (Wagner et al., 2004). The telescope could be adjusted by a stepper motor to any elevation angle between horizon and zenith. In order to prevent influences on the telescope viewing directions caused by rolling and pitching of the vessel, the telescope was mounted on a Cardanic suspension which largely compensated for these movements. The sunlight was focused on a quartz fibre bundle using a quartz lens in order to reach the spectrometer, a commercial instrument with $300 \mathrm{~mm}$ focal length (Acton model 300). The spectra were recorded by a two-dimensional imaging CCD-detector (Andor model DV420-OE). While the spectrometer was heated to a stable temperature of $+32^{\circ} \mathrm{C}$, the CCD-detector was cooled to $-30^{\circ} \mathrm{C}$ for the reasons described above. The spectrometer covered the wavelength range of $325-460 \mathrm{~nm}$ and had a resolution of about $0.7 \mathrm{~nm}$ FWHM.

Both setups were operated by fully automated measurement routines - Doasis (DOAS Intelligent System) (Kraus, 2001) at MIT and a specialized measurement program (Frieß, 2001) on the RV Ron Brown. Both programs employed routines to adapt the integration time of the measurements to the light conditions in order to achieve a constant signal level (i.e. constant signal maximum per exposure), to store the spectra and to control the pointing of the telescopes. The instrument slit functions were determined by measuring the emission line of a mercury lamp at $436 \mathrm{~nm}$.

Scattered sunlight spectra were acquired sequentially at elevation angles of $3^{\circ}, 6^{\circ}, 10^{\circ}, 18^{\circ}$ and from the zenith for both devices (the field of view of both was about $1^{\circ}$ ) so that the viewing direction changed after each measurement. A measurement sequence of the five elevation angles was completed after approximately $5-15 \mathrm{~min}$.

\section{The DOAS analysis}

The CHOCHO DSCDs were derived from the recorded spectra by an analysis procedure using the Windoas software package (Fayt and van Roozendael, 2001) from IASB (Belgium Institute for Space Aeronomy). To the logarithm of the measured spectrum, several trace gas cross sections as well as the logarithm of a Fraunhofer reference spectrum (FRS), a Ring spectrum (Grainger and Ring, 1962) and a polynomial of degree 5 are fitted based on a non-linear least squares fitting algorithm. The zenith spectrum from the previous 
MIT Cambridge, 26 July 2004
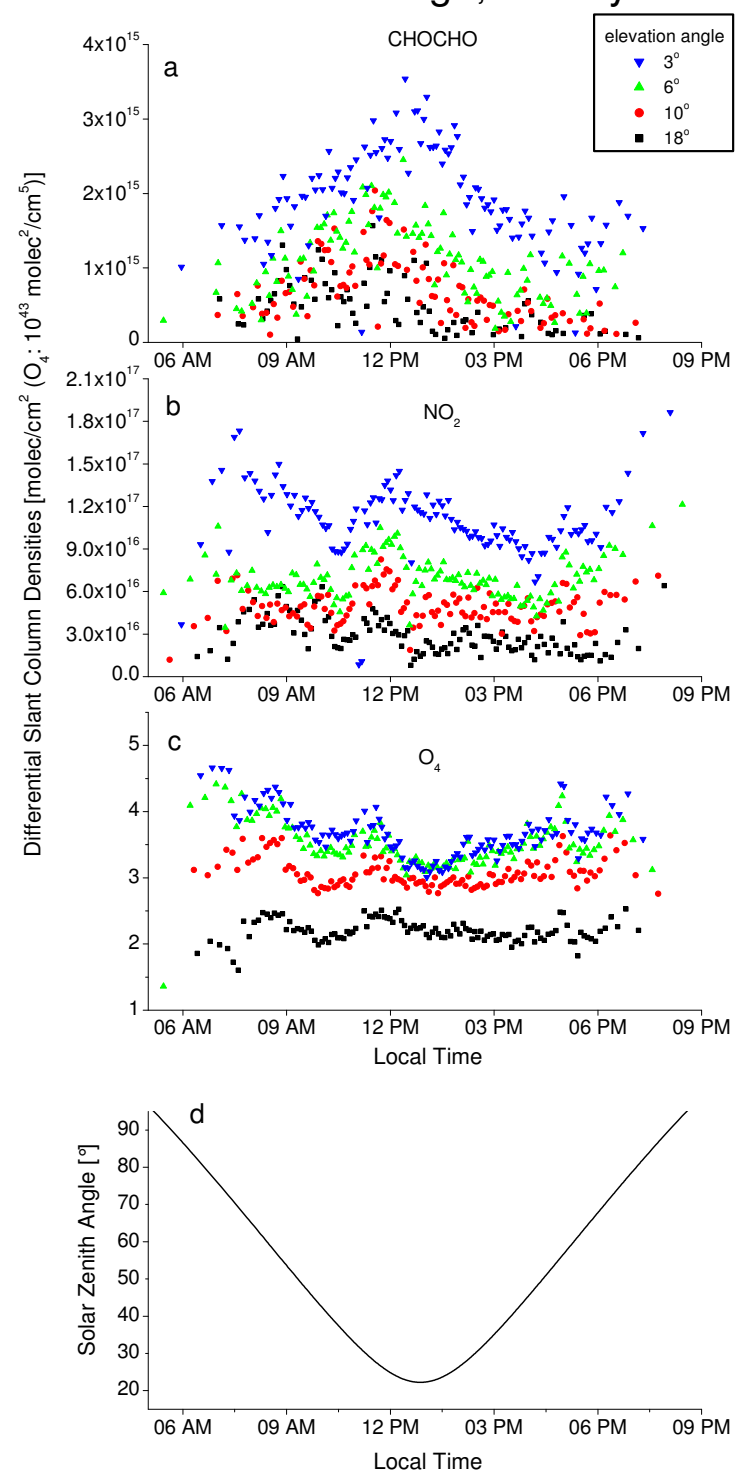

RV Ron Brown, 17 July 2004
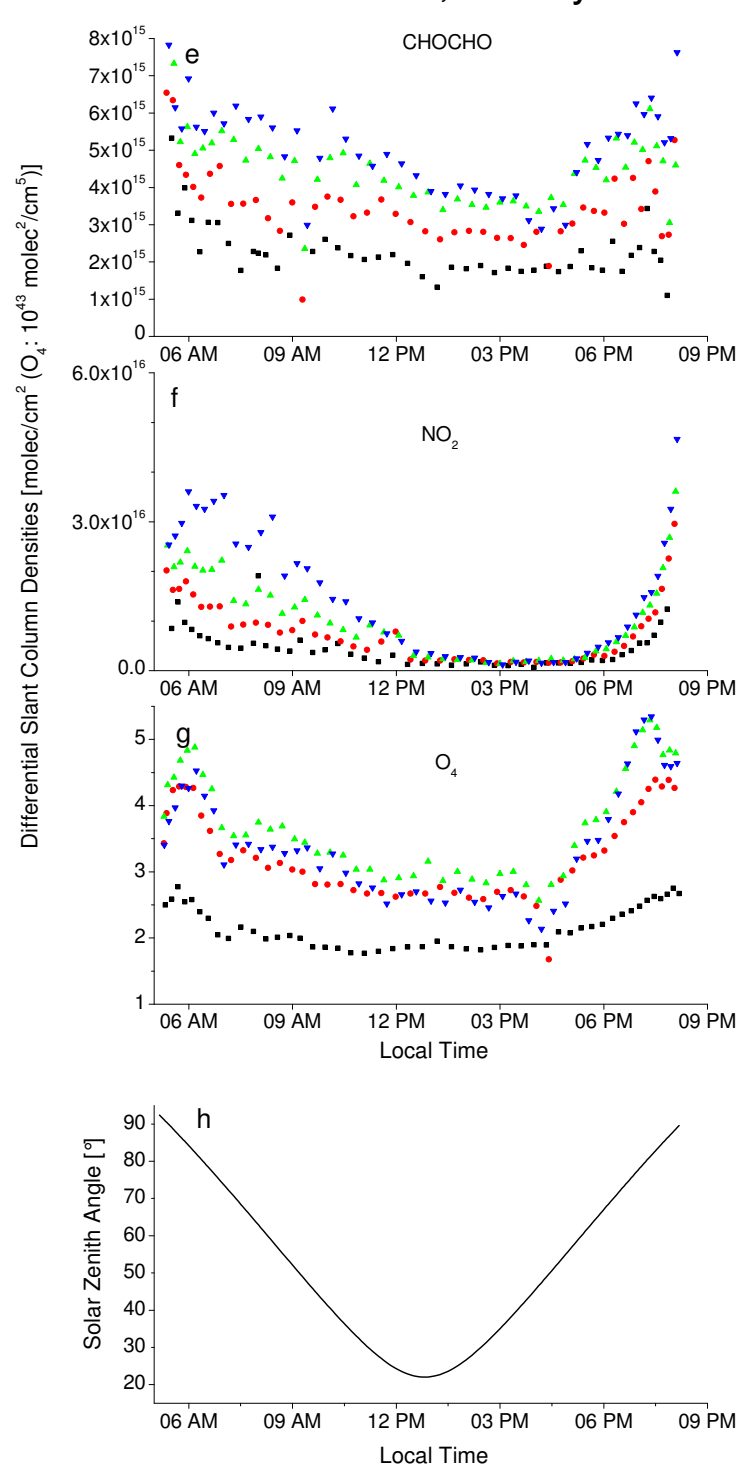

Fig. 2. DSCDs of $\mathrm{CHOCHO}, \mathrm{NO}_{2}$ and $\mathrm{O}_{4}$ at MIT in Cambridge on 26 July 2004 (a-c) and RV Ron Brown on 17 July 2004 (e-g). The elevation angles are indicated by the symbol color as denoted in the legend. In (d) and (h) the solar zenith angle at MIT and RV Ron Brown, respectively, is plotted.

measurement sequence (see above) was chosen as FRS so that it was updated from sequence to sequence. This procedure leads to minimal influence of instrumental instabilities and largely to an elimination of the stratospheric contribution to the DSCD (of course for CHOCHO no stratospheric contribution is expected). The Ring spectrum and the polynomial correct for Raman scattering as well as Rayleigh and aerosol scattering, respectively. The Ring spectrum was calculated from the respective FRS for each sequence and thus changed from sequence to sequence, too. Also, included in the fitting routine was an intensity offset (polynomial of de- gree 1) to account for possible instrumental stray light. The measurement spectrum was allowed to shift against the FRS, the Ring spectrum and the cross sections (Stutz and Platt, 1996). The wavelength calibration was performed using the Doasis software by fitting the Fraunhofer reference spectra to a high resolution Fraunhofer spectrum (Kurucz et al., 1984) convolved with the instrument's slit function (see above).

The following high resolution absorption cross sections were included in the retrieval: CHOCHO (Volkamer et al., 2005b), $\mathrm{NO}_{2}$ (Vandaele et al., 1997), ozone at $223 \mathrm{~K}$ (Bogumil et al., 2003) and $\mathrm{O}_{4}$ (Greenblatt et al., 1990) with manual 
adjustments of the wavelength axis (A. Richter, personal communication). These cross sections were convolved with the instrumental slit function to match the spectral resolution of the instruments (except the $\mathrm{O}_{4}$ spectrum which was interpolated). In addition, we used a water vapor reference spectrum derived from our own atmospheric measurements. This was done because the literature water vapor cross sections are still of poor quality, especially in the wavelength range used in our retrievals. The measured water vapor reference spectrum was derived from the ratio of two spectra (Solomon et al., 1989; Heintz et al., 1996; Wagner et al., 2000), one with high (at $3^{\circ}$ elevation) and one with low water vapor absorption (at zenith direction). In order to minimize the potential interference with $\mathrm{CHOCHO}$ absorption we restricted our measured water vapor reference spectra to the wavelength range of the actual water vapor absorption (from 438.5 to $454 \mathrm{~nm}$ ). For the MIT instrument, the morning of 17 July 2004, when the humidity was high, was selected. The same was done for the RV Ron Brown by using observations performed on 6 July 2004, also a day with water vapor amounts above average. The water vapor measurement was taken at about 07:00 a.m. and 06:00 a.m., respectively, when the least amount of $\mathrm{CHOCHO}$ is expected to be present in the atmosphere. Since the water vapor reference spectra were derived by the instruments themselves, their specific optical properties are inherently leading to a better spectral retrieval with less systematic structures. For the $\mathrm{CHOCHO}$ evaluation, the spectral range from 420 to $460 \mathrm{~nm}$ was chosen $(458 \mathrm{~nm}$ on the RV Ron Brown due to the restricted spectral range of the instrument), encompassing three main $\mathrm{CHOCHO}$ absorption bands.

While the DSCDs of $\mathrm{NO}_{2}$ were retrieved together with $\mathrm{CHOCHO}, \mathrm{O}_{4}$ was analyzed in the wavelength range between 338 and $364 \mathrm{~nm}$ encompassing two absorption bands. Cross sections of $\mathrm{O}_{4}$ (Greenblatt et al., 1990) with manual adjustments of the wavelength axis (A. Richter, personal communication), $\mathrm{NO}_{2}$ (Vandaele et al., 1997), $\mathrm{BrO}$ (Wilmouth et al., 1999), HCHO (Meller and Moortgat, 2000) and of $\mathrm{O}_{3}$ (Bogumil et al., 2003) at two temperatures (243 K and $223 \mathrm{~K}$ ) were fitted. Furthermore, a Ring spectrum, a polynomial of degree 3 and an intensity offset of degree 2 were included in the fit.

Typically, $\mathrm{NO}_{2}$ is the dominant absorber in the retrieval and its absorption cross section shows characteristic structures. Thus, even small potential errors in the analysis of the $\mathrm{NO}_{2}$ absorption (e.g. due to the temperature dependence of the cross section or due to an inaccurate wavelength calibration) might substantially affect the retrieved $\mathrm{CHOCHO}$ results. In this case, the $\mathrm{CHOCHO}-$ to- $\mathrm{NO}_{2}$ ratio should provide an indication of a potential interference with $\mathrm{NO}_{2}$. Since the CHOCHO-to- $\mathrm{NO}_{2}$ ratio shows a variable behavior for each elevation angle and for both sites (for $3^{\circ}$ elevation angle see Fig. 5) such an interference could be clearly excluded.

Several sensitivity studies were performed in order to quantify any systematic error in the CHOCHO retrieval. We

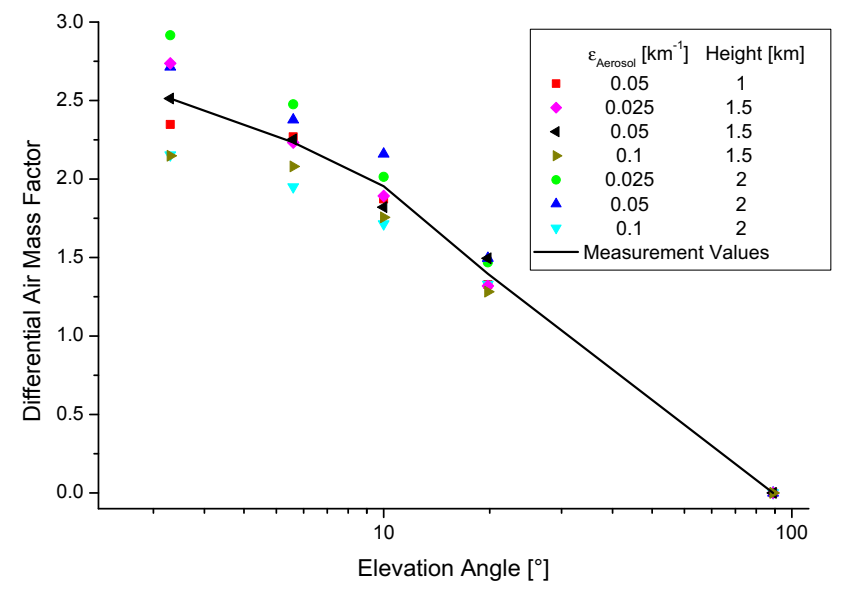

Fig. 3. From measurements calculated $\mathrm{O}_{4}$ DAMFS (black line) compared with modeled $\mathrm{O}_{4}$ DAMF for different homogenously mixed aerosol layers (see legend) as a function of the logarithm of the elevation angle for an SZA of about $40^{\circ}$ at MIT.

varied the wavelength range and the degree of the polynomial as well as of the intensity offset. Furthermore, we used a water vapor cross section from literature (Rothman et al., 1998) instead of our measured water vapor reference spectrum. While the residual structures were significantly larger, the results for $\mathrm{CHOCHO}$ were almost the same as for our original settings. This indicates that our retrieved water vapor reference indeed does not contain significant absorption structures of CHOCHO. Finally, for the measurements at MIT we also used a measured $\mathrm{NO}_{2}$ reference spectrum instead of the cross section taken from literature (for the RV Ron Brown no measured $\mathrm{NO}_{2}$ spectrum was available). It was measured in the early afternoon of 12 July 2004, a slightly hazy, but sunny day with constant lighting conditions, from two zenith spectra one with and one without a $\mathrm{NO}_{2}$ cell in the field of view. For the described sensitivity studies the results for $\mathrm{CHOCHO}$ were robust within $\pm 15 \%$.

\section{Profile inversion}

In the following, we give a short overview on the inversion procedure Sinreich et al. (2005) employed to convert the measured DSCDs into aerosol optical densities (AODs) and trace gas mixing ratios. In a first step, this procedure exploits the fact that the concentration of $\mathrm{O}_{4}$ is proportional to the square of the $\mathrm{O}_{2}$ concentration, which has only a small spatial and temporal variability caused by pressure and temperature changes. Variations of the $\mathrm{O}_{4}$ DSCDs thus mainly reflect changes in the optical properties of the atmosphere. Therefore, $\mathrm{O}_{4}$ delivers information on the light paths through the atmosphere and can be considered as a good indicator for the aerosol load (Wagner et al., 2004; Frieß et al., 2006). $\mathrm{O}_{4}$ DAMFs were simulated for various aerosol scenarios using 
MIT Cambridge, 26 July 2004

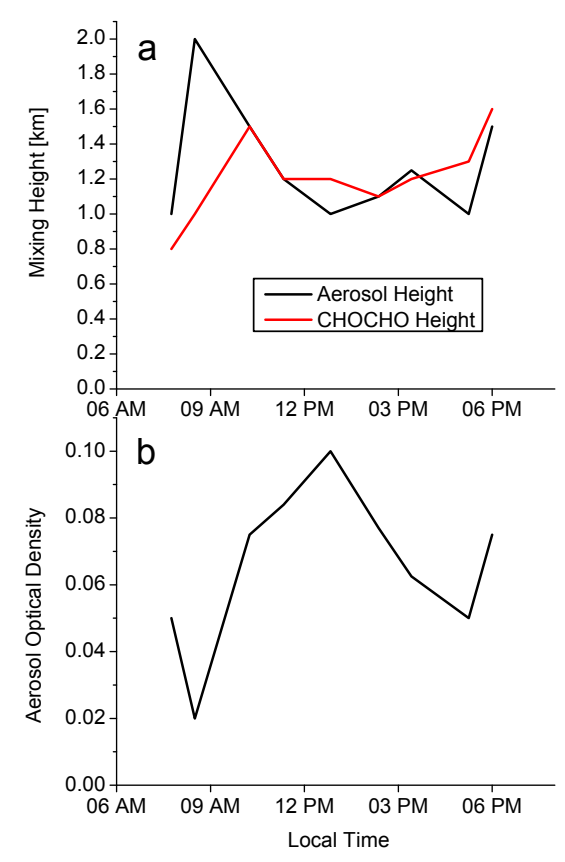

RV Ron Brown, 17 July 2004

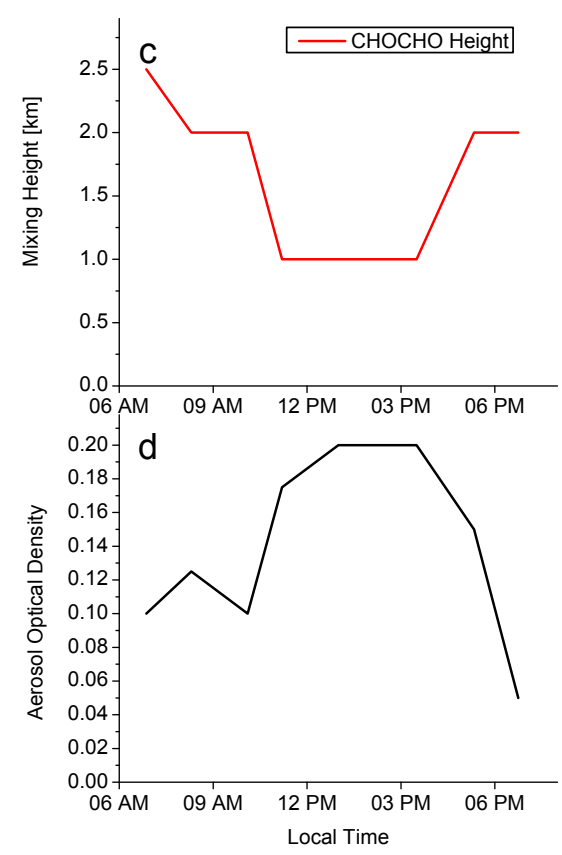

Fig. 4. Estimated mixing height for CHOCHO and aerosol (only for MIT) as well as aerosol optical density at MIT in Cambridge on 26 July 2004 (a and b) and RV Ron Brown on 17 July 2004 (c and d) retrieved by radiative transfer modeling.

the radiative transfer model "Tracy" (v. Friedeburg, 2003). They were compared to the measured $\mathrm{O}_{4}$ DAMFs of the different elevation angles, which were obtained by dividing the $\mathrm{O}_{4}$ DSCDs by a typical $\mathrm{O}_{4} \mathrm{VCD}$. For the simulation, the aerosols were assumed to be homogeneously mixed in the planetary boundary layer (PBL), and the mixing height $H$ and aerosol extinction coefficient $\varepsilon_{\text {Aerosol }}$ were varied. The $(H$, $\left.\varepsilon_{\text {Aerosol }}\right)$ pair (the product of which is the AOD) that best represented the $\mathrm{O}_{4}$ DSCD measurements was then used to calculate DAMFs for CHOCHO. The concentrations of the trace gases also were assumed to be constant in the PBL. The comparison of the ratio between the $3^{\circ}$ and the $18^{\circ}$ values of the modeled DAMFs and of the measured DSCDs yields $H$, which allows deriving the mixing ratio.

This method does not primarily focus on the inversion of the specific properties of the aerosol which due to the used small wavelength range are not impossible but at least difficult to retrieve. Our approach aims at modeling of the optical properties of the aerosol which fit to the $\mathrm{O}_{4}$ measurements and applying them for the inversion of the trace gases. Thereby, ambiguities of the specific aerosol properties can occur. Also, the assumption of well-mixed aerosol and trace gas layers is a rough, but not necessarily a totally unrealistic estimate. In future work, more detailed trace gas profiles could be retrieved, if the information of all elevation angles is used in the trace gas profile retrieval, which was already done by Heckel et al. (2005).

Owing to the strong dependence of the measured DSCDs on the elevation angle, such a profile inversion in principle can be done for each sequence of elevation angles. In this study, we applied the profile inversion for observations averaged over about one hour. This reduces atmospheric variations as well as measurement noise of single observations. The comparisons were performed for solar zenith angles of $25^{\circ}, 30^{\circ}, 40^{\circ}, 60^{\circ}$ as well as $70^{\circ}$ (MIT) and $75^{\circ}$ (RV Ron Brown), respectively.

\section{Results and discussion}

Elevated concentrations of $\mathrm{CHOCHO}$ were detected at MIT in Cambridge and onboard RV Ron Brown on more than 10 days during the measurement period. The DSCDs are generally significantly lower at MIT than onboard RV Ron Brown.

An example for the retrieval of $\mathrm{CHOCHO}$ from the instrument onboard the RV Ron Brown is shown in Figure 1. The spectrum was taken under sunny conditions on 10 July 2004, at about 05:15 p.m. at an elevation angle of $3^{\circ}$. At this time, the vessel was cruising along the coast of Massachusetts $\left(42.09^{\circ} \mathrm{N}, 70.59^{\circ} \mathrm{W}\right)$ with wind from westward directions. The optical densities of the fitted components as a function of wavelength are shown in black, whereas the red lines show the sum of the scaled crosssections and the residual. The root mean square variation of the residual (Fig. 1f) in this evaluation is $0.34 \times 10^{-3}$ which is less than one tenth of the retrieved optical density 
MIT Cambridge, 26 July 2004

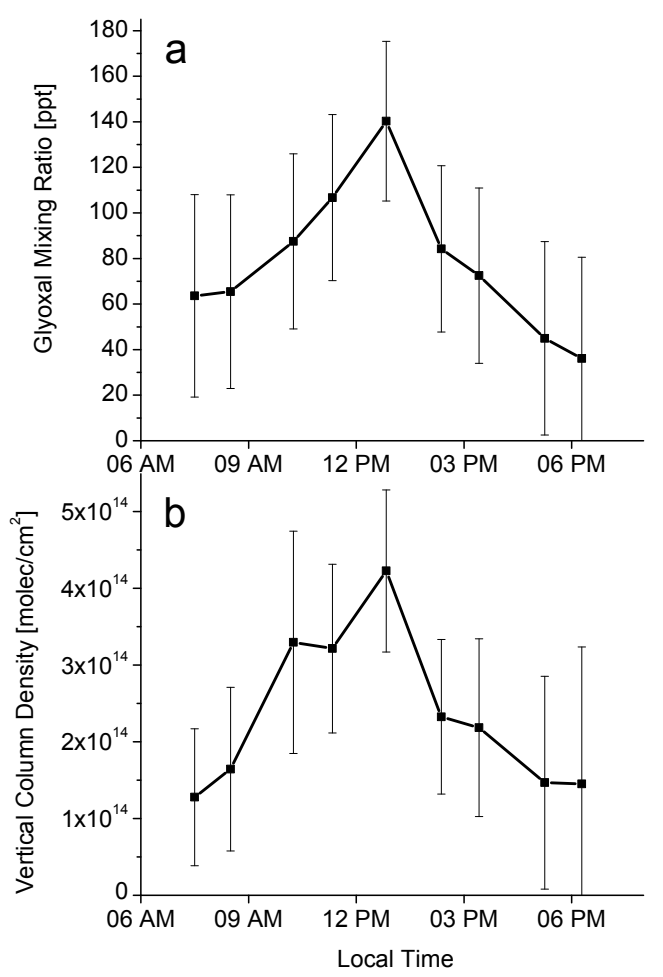

RV Ron Brown, 17 July 2004

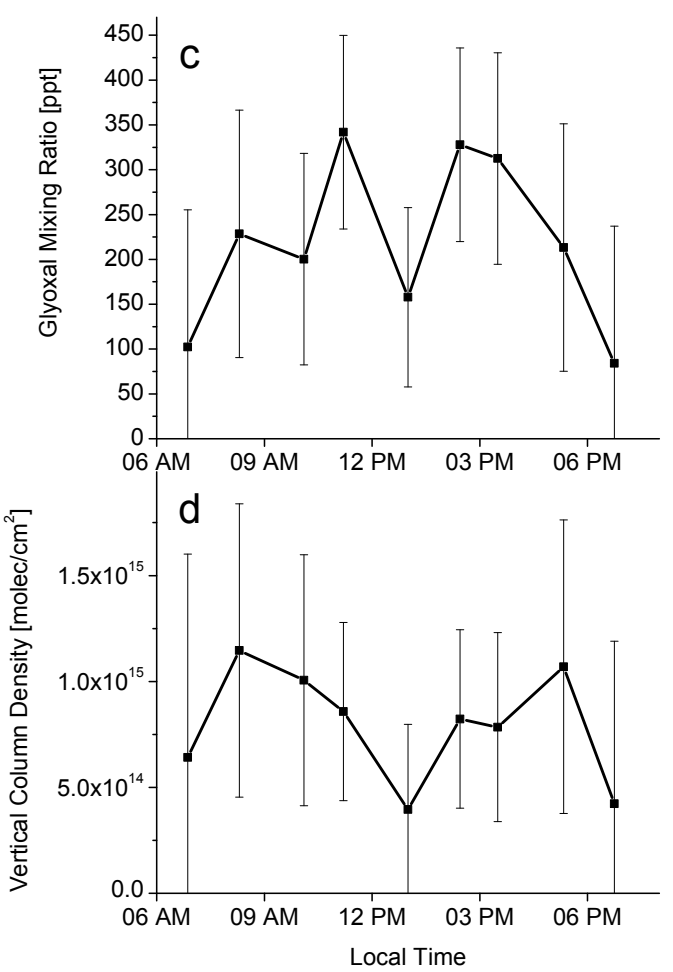

Fig. 5. CHOCHO mixing ratios and VCDs at MIT in Cambridge on 26 July 2004 (a and b) and RV Ron Brown on 17 July 2004 (c and d) retrieved by radiative transfer modeling from $\mathrm{CHOCHO}$ DSCDs.

of CHOCHO (approx. $3.5 \times 10^{-3}$ ) and therefore is clearly low enough to allow an unambiguous detection of $\mathrm{CHOCHO}$ (Stutz and Platt, 1996). The corresponding DSCD amounts to $6.74 \times 10^{15} \mathrm{molec} / \mathrm{cm}^{2}$ at a $1 \sigma$ error of $3.00 \times 10^{14}$. The DSCDs of $\mathrm{NO}_{2}\left(3.55 \times 10^{16} \mathrm{molec} / \mathrm{cm}^{2}\right)$, water vapor, $\mathrm{O}_{4}$ and $\mathrm{O}_{3}$ are also clearly identified.

In Fig. 2, measured tropospheric DSCDs of CHOCHO, $\mathrm{NO}_{2}$ and $\mathrm{O}_{4}$ as well as the solar zenith angles are plotted for both sites, each on a clear day, which can be identified by a relatively smooth variation of the $\mathrm{O}_{4}$ DSCDs during the day. At MIT, the chosen day is 26 July, which showed an increase in the CHOCHO DSCDs (Fig. 2a) up to about $3.5 \times 10^{15} \mathrm{molec} / \mathrm{cm}^{2}$ in the morning, indicating a very efficient VOC oxidation on that day. In the afternoon, the values decreased again most probably caused by chemical loss. Especially the MAX-DOAS observations at high elevation angles (e.g. $18^{\circ}$ ) are sensitive for the total VCD and consequently just a dilution effect in a rising PBL would hardly affect the CHOCHO DSCDs (of course this is different at low elevation angles). The described behavior of the CHOCHO DSCDs is consistent with active DOAS observations in Mexico City (Volkamer et al., 2005a). The $\mathrm{NO}_{2}$ DSCDs do not show such a pronounced diurnal cycle, although a decrease in the afternoon can also be observed. The diurnal variation of the $\mathrm{NO}_{2}$ values appears to be dominated by light path changes, as can be seen from the similarity to the variation in the $\mathrm{O}_{4}$ DSCDs. 17 July was a clear day for the RV Ron Brown. On this day, the vessel cruised around $69^{\circ} \mathrm{W}$ and $43^{\circ} \mathrm{N}$ in the Gulf of Maine mainly in eastward direction, at about the same latitude as Portsmouth, New Hampshire. The wind came from southwest to west during the day. Here the CHOCHO DSCDs (Fig. 2e) are more influenced by the light path variations whereas the $\mathrm{NO}_{2}$ DSCDs show high tropospheric $\mathrm{NO}_{2}$ in the morning which disappeared in the afternoon. In the late afternoon, the course of the vessel changed to northwest and a new air mass with slightly less aerosol load seemed to be present. For both days, radiative transfer modeling was performed to convert DSCDs into mixing ratios. For these calculations, an $\mathrm{O}_{4}$ cross section value of $5 \times 10^{46} \mathrm{~cm}^{5} / \mathrm{molec}^{2}$ (for the $361 \mathrm{~nm}$ absorption band) was assumed (for the definition of the $\mathrm{O}_{4}$ cross section see Greenblatt et al., 1990). Figure 3 shows an example of the aerosol retrieval at MIT in the morning (about $40^{\circ}$ SZA). $\mathrm{O}_{4}$ DAMFs calculated from the measurement (black line) are compared with modeled $\mathrm{O}_{4}$ DAMFs at different homogenously mixed aerosol layers. Owing to clearness the number of scenarios was reduced here. Obviously, the third scenario (black) matches best to the measurement values.

In Fig. 4, the estimated profile heights $H$ and AODs are shown for both sites. The aerosol and $\mathrm{CHOCHO}$ profile 

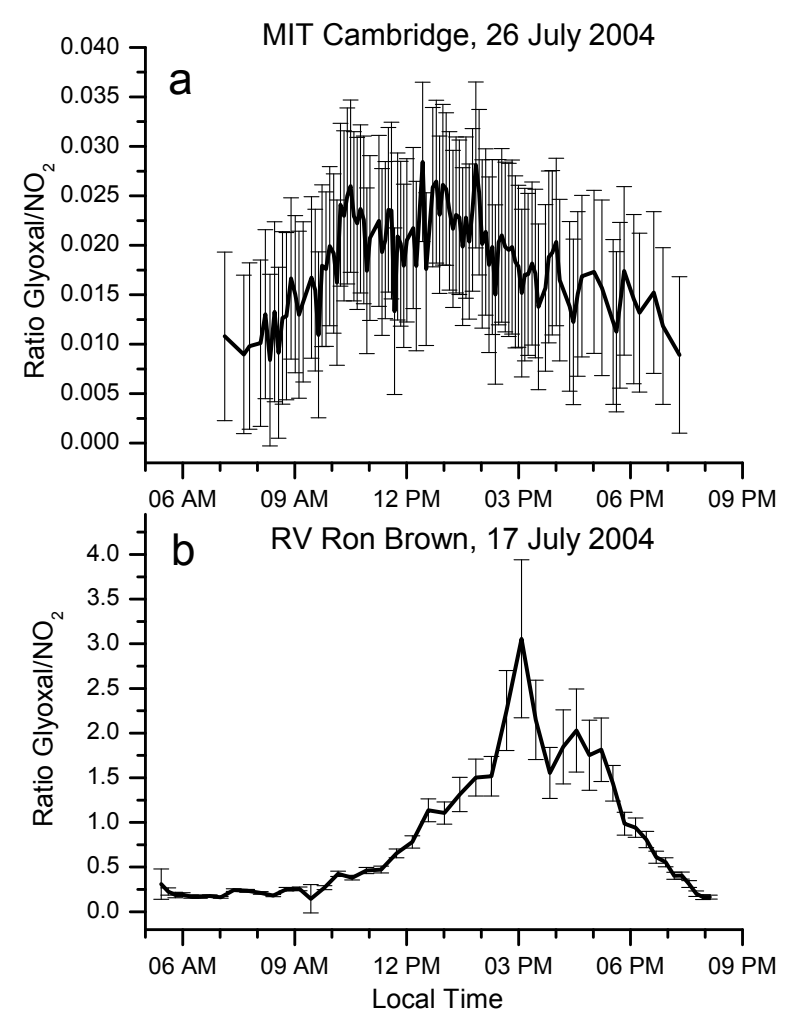

Fig. 6. $\mathrm{CHOCHO}-$ to- $\mathrm{NO}_{2}$ DSCD ratios of the $3^{\circ}$ elevation values at MIT in Cambridge on 26 July 2004 (a) and RV Ron Brown on 17 July 2004 (b).

heights at MIT generally match well, except for some deviations in the morning and evening, when CHOCHO DSCDs were lowest. During mid-day, the signal to noise ratio of the DSCDs is highest and the radiative transfer modeling is more accurate. At RV Ron Brown, the modeling of the aerosol layer height did not lead to an unequivocal result due to the relatively high AOD (of course, in reality even much higher AODs can occur. Nevertheless, the sensitivity of the $\mathrm{O}_{4}$ absorption on the AOD decreases with increasing AOD) and possibly the complexity of the real aerosol scenario. The AOD at MIT peaked around noon, but generally increased in the course of the day which indicates an accumulation of aerosol load during that day. At RV Ron Brown, an accumulation can also be observed whereas a sudden decrease in the late afternoon indicates an altered air mass as already seen in the DSCDs.

The resulting CHOCHO mixing ratios at MIT (Fig. 5a) have their maximum at noon with about $140 \pm 35 \mathrm{ppt}(1 \mathrm{ppt}$ $=1$ part per trillion $=2.51 \times 10^{7} \mathrm{molec} / \mathrm{cm}^{3}$ at $293 \mathrm{~K}$ and 1013 mbar). In contrast, there is no such clear maximum on RV Ron Brown (Fig. 5c) and the maximum values are almost three times higher (up to $340 \pm 110 \mathrm{ppt}$ ). In the MCMA-2003 campaign, values up to $1.82 \mathrm{ppb}(1 \mathrm{ppb}=1$ part per billion = $1000 \mathrm{ppt}$ ) were measured (Volkamer et al., 2005a). Typical daytime maxima were about five times larger in Mexico City than in Cambridge. In Figs. 5b and d the VCDs of MIT and RV Ron Brown, respectively, are plotted which have basicly the same diurnal cycle as the mixing ratios.

Figure 6 shows the $\mathrm{CHOCHO}-$ to- $\mathrm{NO}_{2}$ DSCD ratio at $3^{\circ}$ elevation for the chosen days for the MIT site (Fig. 6a) and the RV Ron Brown (Fig. 6b). At MIT, the ratio reached its maximum $(0.028 \pm 0.008)$ at $12: 30$ p.m., a much smaller value than observed during MCMA-2003 where daily maximum ratios varied between 0.045 and 0.14 (Volkamer et al., 2005a). The MCMA-2003 campaign average ratio (0.081) is two to three times higher than in Cambridge, possibly reflecting differences in the $\mathrm{VOC} / \mathrm{NO}_{\mathrm{x}}$ ratio $\left(\mathrm{NO}_{\mathrm{x}}=\mathrm{NO}+\right.$ $\mathrm{NO}_{2}$ ) between both urban sites. The ratio in Cambridge also peaked relatively late, reflecting more active and earlier PBL dynamics in Mexico City (de Foy et al., 2005) than in Cambridge. In contrast, the ratios onboard RV Ron Brown were much higher and peaked even later in the day. On 17 July 2004 , the ratio reached up to $3.1 \pm 0.9$ at $3 \mathrm{PM}$. This is $110 \pm 45$ times higher than at MIT.

The considerably higher $\mathrm{CHOCHO}-$ to- $\mathrm{NO}_{2}$ ratio over the sea compared to the Cambridge values can partly be explained by the fact that $\mathrm{CHOCHO}$ is a secondary pollutant, i.e. formed from the airborne VOC oxidation, in contrast to $\mathrm{NO}_{2}$ from $\mathrm{NO}_{\mathrm{x}}$ emissions. Sustained CHOCHO formation from longer lived VOC precursor oxidation in combination with $\mathrm{NO}_{\mathrm{x}}$ removal in the photochemical plume will thus lead to higher $\mathrm{CHOCHO}-$ to- $\mathrm{NO}_{2}$ ratios downwind of emission sources. For a rough estimate of the extent of the $\mathrm{NO}_{2}$ removal effect, we assume that the air mass needed half a day to reach the RV Ron Brown from the last emission source (with a distance of about $200 \mathrm{~km}$ and a wind speed of about $5 \mathrm{~m} / \mathrm{s}$ ), and that the air mass contained an $\mathrm{OH}$ concentration of about $2.6 \times 10^{6}$ molecules per $\mathrm{cm}^{3}$. This number is the retrieved $24 \mathrm{~h}$ average $\mathrm{OH}$ concentration during NEAQS-2002 for air masses that had been impacted by major urban areas such as New York City and Boston and by biogenic emissions in New Hampshire and Maine (Warneke et al., 2004). Under these assumptions, only considering the reaction with $\mathrm{OH}$, the lifetime of $\mathrm{NO}_{2}$ amounts to $9.7 \mathrm{~h}$ with a rate coefficient of $1.1 \times 10^{-11} \mathrm{~cm}^{3} / \mathrm{s}$ (from Sander et al., 2003, for $285 \mathrm{~K}$ and $1013 \mathrm{mbar}$ ). After 12 hours, only $29 \%$ of the initial $\mathrm{NO}_{2}$ is present. Together with the measured 2.5 times higher $\mathrm{CHOCHO}$ concentrations, the $\mathrm{CHOCHO}-$ to- $\mathrm{NO}_{2}$ ratio would increase by a factor of about 9 which is one magnitude less than the measured ratio of the CHOCHO-to- $\mathrm{NO}_{2}$ peaks. Thus, it appears likely that there are other processes contributing to the high $\mathrm{CHOCHO}-$ to- $\mathrm{NO}_{2}$ ratio than only $\mathrm{NO}_{\mathrm{x}}$ removal by $\mathrm{OH}$. Such processes could include additional $\mathrm{NO}_{\mathrm{x}}$ sinks, reduced CHOCHO sinks over the Gulf of Maine compared to Cambridge, or an additional CHOCHO source to the atmosphere over the Gulf of Maine. The chemistry influencing the $\mathrm{CHOCHO}-$ to- $\mathrm{NO}_{2}$ ratio requires further investigation, and will be the subject of a forthcoming paper. 


\section{Conclusions}

For the first time glyoxal (CHOCHO) could be detected by passive multi axis differential optical absorption spectroscopy (MAX-DOAS). The measurements were performed in the framework of the International Consortium for Atmospheric Research on Transport and Transformation (ICARTT) 2004 campaign at MIT, Cambridge, USA, and on board the research vessel Ron Brown in the Gulf of Maine. For the retrieval, the absorption bands between 420 and $460 \mathrm{~nm}$ were used and optical densities of $\mathrm{CHOCHO}$ up to $3.5 \times 10^{-3}$ could be detected. Besides the slant column densities of $\mathrm{CHOCHO}$, planetary boundary layer (PBL) heights and mixing ratios in the PBL, which was assumed to be well mixed, could be retrieved for a nearly clear day at each site by means of radiative transfer modeling. Mixing ratios at MIT varied from 40 to $140 \mathrm{ppt}$ while over the Gulf of Maine they were found to be up to three times larger than at MIT. The CHOCHO-to- $\mathrm{NO}_{2}$ ratios showed clear diurnal cycles with maxima in the middle of the day. The ratio over the Gulf of Maine was $110 \pm 45$ times higher than on the chosen day at MIT. $\mathrm{NO}_{\mathrm{x}}$ removal is found to be one responsible factor for this enhancement, but also other factors seem to play a role and will be subject of a companion paper that focuses more on the chemistry involved to explain these observations.

Acknowledgements. Financial support from NOAA for the MAX-DOAS measurements in the ICARTT 2004 Campaign is acknowledged. R. Volkamer acknowledges consecutive fellowships from Camille and Henry Dreyfus Foundation and Alexander von Humboldt Foundation, as well as M. and L. Molina for their help with providing space at MIT.

Edited by: A. Richter

\section{References}

Beirle, S., Volkamer, R., Wittrock, F., Richter, A., Burrows, J., Platt, U., and Wagner, T.: DOAS Retrieval of Glyoxal from Space, Proceedings of the ESA Atmospheric Science Conference, 8-12 May 2006, Frascati, http://earth.esa.int/workshops/atmos2006/participants/1055/ paper_DOAS_retrieval_of_Glyoxal_from_space.pdf, 2006.

Bobrowski, N., Hönninger, G., Galle, B., and Platt, U.: Detection of Bromine Monoxide in a Volcanic Plume, Nature 423, 15 May, 273-276, 2003.

Bogumil, K., Orphal, J., Homann, T., Voigt, S., Spietz, P., Fleischmann, O. C., Vogel, A., Hartmann, M., Bovensmann, H., Frerik, J., and Burrows, J. P.: Measurements of Molecular Absorption Spectra with the SCIAMACHY Pre-Flight Model: Instrument Characterization and Reference Data for Atmospheric Remote-Sensing in the 230-2380 nm Region, J. Photochem. Photobiol. A., 157, 167-184, 2003.

Calvert, J. G., Atkinson, R., Becker, K. H., Kamens, R. H., Seinfeld, J. H., Wallington, T. J., and Yarwood, G.: The mechanisms of atmospheric oxidation of aromatic hydrocarbons, Oxford Univ. Press, Oxford, 2002.

Calvert, J. G., Atkinson, R., Kerr, J. A., Madronich, S., Moortgat, G. K., Wallington, T. J., and Yarwood, G.: The Mechanisms of Atmospheric Oxidation of the Alkenes, Oxford Univ. Press, New York, 2000.

de Foy, B., Caetano, E., Magaña, V., Zitácuaro, A., Cárdenas, B., Retama, A., Ramos, R., Molina, L. T., and Molina, M. J.: Mexico City basin wind circulation during the MCMA-2003 field campaign, Atmos. Chem. Phys., 5, 2267-2288, 2005, http://www.atmos-chem-phys.net/5/2267/2005/.

Fayt, C. and Roozendael, M.: WinDOAS 2.1. Software User Manual, 2001.

Frieß, U., Monks, P. S., Remedios, J. J., Rozanov, A., Sinreich, R., Wagner, T., and Platt, U.: MAX-DOAS $\mathrm{O}_{4}$ measurements: A new technique to derive information on atmospheric aerosols: 2. Modeling studies, J. Geophys. Res., 111, D14203, doi:10.1029/2005JD006618, 2006.

Frieß, U.: Spectroscopic Measurements of Atmospheric Trace Gases at Neumayer-Station, Antarctica, PhD Thesis, University of Heidelberg, http://deposit.ddb.de/cgi-bin/dokserv?idn= 962363928, 2001.

Galle, B., Oppenheimer, C., Geyer, A., McGonigle, A., Edmonds, M., and Horrocks, L.: A miniaturised ultraviolet spectrometer for remote sensing of $\mathrm{SO}_{2}$ fluxes: a new tool for volcano surveillance, J. Volc. Geotherm. Res., 119, 214-254, 2003.

García, A. R., Volkamer, R., Molina, L. T., Molina, M. J., Samuelson, J., Mellqvist, J., Galle, B., Herndon, S. C., and Kolb, C. E.: Separation of emitted and photochemical formaldehyde in Mexico City using a statistical analysis and a new pair of gas-phase tracers, Atmos. Chem. Phys., 6, 4545-4557, 2006

Grainger, J. F. and Ring, J.: Anomalous Fraunhofer line profiles, Nature, 193, 762, 1962.

Greenblatt, G. D., Orlando, J. J., Burkholder, J. B., and Ravishankara, A. R.: Absorption measurements of oxygen between 330 and 1140 nm, J. Geophys. Res. 95, 18 577-18 582, 1990.

Heckel, A., Richter, A., Tarsu, T., Wittrock, F., Hak, C., Pundt, I., Junkermann, W., and Burrows, J. P.: MAX-DOAS measurements of formaldehyde in the Po-Valley, Atmos. Chem. Phys., 5, 909918, 2005, http://www.atmos-chem-phys.net/5/909/2005/.

Heintz, F., Platt, U., Flentje, H., and Dubois, R.: Longterm observation of nitrate radicals at the Tor Station, Kap Arkona (Rügen), J. Geophys. Res., 101(D17), 22 891-22910, doi:10.1029/96JD01549, 1996.

Hönninger, G., Friedeburg, C.v., and Platt, U.: Multi Axis Differential Absorption Spectroscopy (MAX-DOAS), Atmos. Chem. Phys., 4, 231-254, 2004, http://www.atmos-chem-phys.net/4/231/2004/.

Hönninger, G. and Platt, U.: The Role of BrO and its Vertical Distribution during Surface Ozone Depletion at Alert, Atmos. Environ., 36, 2481-2489, 2002.

Kurosu, T. P., Chance, K., and Volkamer, R.: Global Measurements of $\mathrm{OClO}, \mathrm{BrO}, \mathrm{HCHO}$, and $\mathrm{CHO}-\mathrm{CHO}$ from the Ozone Monitoring Instruments on EOS Aura, Eos Trans. AGU, Fall Meet. Suppl., Abstract A54B-01, 5-9 Dec. 2005, San Francisco, CA, USA, 2005.

Kraus, S.: The DOASIS software, Chapter Presentation at the 1st international DOAS Workshop, Heidelberg, Germany, 2001. 
Kroll, J., Ng, N. L., Murphy, S. M., Varutbangkul, V., Flagan, R. C., and Seinfeld, J. H.: Chamber studies of secondary organic aerosol growth by reactive uptake of simple carbonyl compounds, J. Geophys. Res., 110, D23207, doi:10.1029/2005JD006004, 2005.

Kurucz, R. L., Furenlid, I., J., and Testerman, L.: Solar Flux Atlas from 296 to $1300 \mathrm{~nm}$, Technical Report, National Solar Observatory, 1984.

Leser H., Hönninger G., and Platt, U.: MAX-DOAS Measurements of $\mathrm{BrO}$ and $\mathrm{NO}_{2}$ in the Marine Boundary Layer, Geophys. Res. Lett. 30(10), 1537, doi:10.1029/2002GL015811, 2003.

Liggio, J., Li, S.-M., and McLaren, R.: Reactive uptake of glyoxal by particulate matter, J. Geophys. Res., 110, D10304, doi:10.1029/2004JD005113, 2005.

Marquard, L. C., Wagner, T., and Platt, U.: Improved Air Mass Factor Concepts for Scattered Radiation Differential Optical Absorption Spectroscopy of Atmospheric Species, J. Geophys. Res., 105, 1315-1327, 2000.

Meller, R. and Moortgat, G. K.: Temperature dependence of the absorption cross sections of formaldehyde between 223 and $323 \mathrm{~K}$ in the wavelength range $225-375 \mathrm{~nm}$, J. Geophys. Res., 105, 7089-7101, 2000.

Otten, C., Ferlemann, F., Platt, U., Wagner, T., and Pfeilsticker, K.: Groundbased DOAS UV/visible measurements at Kiruna (Sweden) during the SESAME winters 1993/94 and 1994/95, J. Atmos. Chem., 30, 141-162, 1998.

Platt, U.: Differential optical absorption spectroscopy (DOAS), Air monitoring by spectroscopic techniques, M.W. Sigrist, Ed., Chemical Analysis Series, 127, John Wiley \& Sons, Inc., 1994.

Platt, U.: Modern Methods of the Measurement of Atmospheric Trace Gases, J. Phys. Chem. Chem. Phys. 'PCCP' 1, 5409-5415, 1999.

Rothman, L. S., Rinsland, C. P., Goldman, A., Massie, S. T., Edwards, D. P., Flaud, J. M., Perrin, A., Camy-Peyret, C., Dana, V., Mandin, J. Y., Schroeder, J., McCann, A., Gamache, R. R., Wattson, R. B., Yoshino, K., Chance, K. V., Jucks, K. W., Brown, L. R., Nemtchinov, V., and Varanasi, P.: The HITRAN Molecular Spectroscopic Database and HAWKS (HITRAN Atmospheric Workstation), Edition. J. Quant. Spec. and Rad. Transf. 60, 665/710, 1998.

Sander, S. P., Friedl, R. R., Golden, D. M., Kurylo, M. J., Huie, R. E., Orkin, V. L., Moortgat, G. K., Ravishankara, A. R., Kolb, C. E., Molina, M. J., and Finlayson-Pitts, B. J.: Chemical Kinetics and Photochemical Data for Use in Atmospheric Studies, Tech. Rep. JPL Publication 02-25, Jet Propulsion Laboratory, Pasadena, CA, 2003.

Sinreich, R., Filsinger, F., Kern, C., Platt, U., Sebastián, O., Wagner, T., and Volkamer, R.: MAX-DOAS measurement of Glyoxal at the MIT in Cambridge during the NEAQS-ITCT 2004 Campaign, AGU, Abstract A11A-0011, 13-17 Dec. 2004, San Francisco, CA, USA, 2004.

Sinreich, R., Frieß, U., T., and Platt, U.: Multi axis differential optical absorption spectroscopy (MAX-DOAS) of gas and aerosol distributions, Faraday Discuss., 130(08), doi:10.1039/b419274, 2005.

Solomon, S., Schmeltekopf, A. L., and Sanders, R. W.: On the interpretation of zenith sky absorption measurements, J. Geophys. Res, 92, 8311-8319, 1987.

Solomon, S., Miller, H. L., Smith, J. P., Sanders, R. W., Mount,
G. H., Schmeltekopf, A. L., and Noxon, J. F.: Atmospheric $\mathrm{NO}_{3}$ 1. Measurement technique and the annual cycle at $40^{\circ} \mathrm{N}, \mathrm{J}$. Geophys. Res., 94(D8), 11041-11048, doi:10.1029/89JD00605, 1989.

Stutz, J. and Platt, U.: Numerical Analyses and Estimation of the Statistical Error of Differential Optical Absorption Spectroscopy Measurements with Least Square Methods, Appl. Opt., 35, 6041-6053, 1996.

v. Friedeburg, C.: Derivation of Trace Gas Information combining Differential Optical Absorption Spectroscopy with Monte Carlo Radiative Transfer Modelling, PhD Thesis, University of Heidelberg, 2003.

v. Friedeburg, C., Pundt, I., Mettendorf, K.-U., Wagner, T., and Platt, U.: Multi-AXis-(MAX) DOAS Measurements of $\mathrm{NO}_{2}$ during the BAB II Motorway Emission Campaign, (BAB II special issue) Atmos. Environ. 39, 5, 977-985, doi:10.1016/j.atmosenv.2004.06.046, 2005.

van Roozendael, M., Fayt, C., Post, P., Hermans, C., and Lambert, J.-C.: Retrieval of $\mathrm{BrO}$ and $\mathrm{NO}_{2}$ from UV-Visible Observations, in: Sounding the troposphere from space: a new era for atmospheric chemistry, Springer-Verlag, ISBN 3-540-40873-8, edited by: Borell, P., Borell, P. M., Burrows, J. P., and Platt, U., 2003.

Vandaele, A. C., Hermans, C., Simon, P. C., Carleer, M., Colin, R., Fally, S., Mérienne, M.-F., Jenouvrier, A., and Coquart, B.: Measurements of the NO2 Absorption Cross-section from $42000 \mathrm{~cm}^{-1}$ to $10000 \mathrm{~cm}^{-1}(238-1000 \mathrm{~nm})$ at $220 \mathrm{~K}$ and 294 K, J. Quant. Spectrosc. Radiat. Transfer, 59, 171-184, 1997.

Volkamer, R., Platt, U., and Wirtz K.: Primary and Secondary Glyoxal Formation from Aromatics: Experimental Evidence for the Bicycloalkyl-Radical Pathway from Benzene, Toluene, and pXylene, J. Phys. Chem. A, 105, 7865-7874, 2001.

Volkamer, R., Molina, L. T., Molina, M. J., Shirley, T., and Brune, W. H.: DOAS measurement of glyoxal as an indicator for fast VOC chemistry in urban air, J. Geophys. Res., 32, L08806, doi:10.1029/2005GL022616, 2005a.

Volkamer, R., Spietz, P., Burrows, J. P., and Platt, U.: High-resolution absorption cross-section of Glyoxal in the UV/vis and IR spectral ranges, Journal of Photochemistry and Photobiology A: Chemistry 172 (2005), 35-46. doi:10.1016/j.jphotochem.2004.11.011, 2005b.

Volkamer, R., Jimenez, J. L., San Martini, F., Dzepina, K., Zhang, Q., Salcedo, D., Molina, L. T., Worsnop, D. R., and Molina, M. J.: Secondary Organic Aerosol Formation from Anthropogenic Air Pollution: Rapid and Higher than Expected, Geophys. Res. Lett., 33(17) L17811, doi:10.1029/2006GL026899, 2006.

Wagner, T., Otten, C., Pfeilsticker, K., Pundt, I., and Platt, U.: DOAS moonlight observation of atmospheric $\mathrm{NO}_{3}$ in the Arctic winter, Geophys. Res. Lett., 27(21), 3441-3444, doi:10.1029/1999GL011153, 2000.

Wagner, T., Dix, B., Friedeburg, C. v., Frieß, U., Sanghavi, S., Sinreich, R., and Platt, U.: MAX-DOAS $\mathrm{O}_{4}$ measurements: A new technique to derive information on atmospheric aerosols - Principles and information content, J. Geophys. Res., 109, D22205, doi:10.1029/2004JD004904, 2004.

Warneke, C., de Gouw, J. A., Goldan, P. D., Kuster, W. C., Williams, E. J., Lerner, B. M., Jakoubek, R., Brown, S. S., Stark, H., Aldener, M., Ravishankara, A. R., Roberts, J. M., Marchewka, M., Bertman, S., Sueper, D. T., McKeen, S. A., Meagher, J. F., and Fehsenfeld, F. C.: Comparison of daytime 
and nighttime oxidation of biogenic and anthropogenic VOCs along the New England coast in summer during New England Air Quality Study 2002, J. Geophys. Res., 109(D10), D10309, doi:10.1029/2003JD004424, 2004.

Wilmouth, D.M., T.F. Hanisco, N.M. Donahue, J.G. Anderson, Fourier transfor ultraviolet spectroscopy of the $A_{3 / 2}^{2 \Pi} \leftarrow X_{3 / 2}^{2 \Pi}$ transition of BrO, J. Phys. Chem. A., 103, 8935-8945, 1999.

Wittrock, F., Oetjen, H., Richter, A., Fietkau, S., Medeke, T., Rozanov, A., and Burrows, J. P.: MAX-DOAS measurements of atmospheric trace gases in Ny-Ålesund - Radiative transfer studies and their application, Atmos. Chem. Phys., 4, 955-966, 2004 ,

http://www.atmos-chem-phys.net/4/955/2004/.
Wittrock, F., Richter, A., Burrows, J. P., Kanakidou, M., Volkamer, R., Beirle, S., Platt, U., and Wagner, T.: Simultaneous Global Observations of Glyoxal and Formaldehyde from Space, Geophys. Res. Lett., 33, L16804, doi:10.1029/2006GL026310, 2006. 